\title{
Testing Weak-Form Market Efficiency of Dhaka Stock Exchange
}

\section{Md. Abu Hasan*}

PhD Fellow, Institute of Bangladesh Studies, Rajshahi University, Rajshahi, BANGLADESH

*Corresponding Contact:

Email: hhafij@yahoo.com

Cell Phone: +8801711282920

\begin{abstract}
Measuring the efficiency of the stock market is an important research topic as there are various implications for investors. This paper investigates the weak form efficiency in the framework of the random walk hypothesis for the stock market in Bangladesh, employing both Non Parametric tests (Runs test and Phillips-Perron test) and Parametric tests (Autocorrelation test, Augmented Dickey-fuller test, and Variance Ratio test). The study uses daily return data for the three stock indices of Dhaka Stock Exchange such as DSI (from 02 January 1993 to 27 January 2013) with a total of 4823 daily return observations, DGEN (from 01 January 2002 to 31 July 2013) with a total of 2903 daily return observations, and DSE-20 (from 01 January 2001 to 27 January 2013) with a total of 3047 daily return observations. The evidence suggests that all the return series do not follow the random walk model, and thus the Dhaka Stock Exchange is inefficient in weak form. Thus, historical stock prices can be used to achieve superior gains from the stock markets in Bangladesh.
\end{abstract}

Keywords: Stock Market, Random Walk Hypothesis, Efficient Market Hypothesis, Runs test, Unit Root Tests, Variance Ratio test

JEL Classification Code: C22, G10, G14

\section{INTRODUCTION}

Stock market regards as an engine of a strong and modern economy considering that it is a more dynamic financial system than a traditional, rigid, and insecure bank based financial system. The stock markets of developed countries obtain more concentration to allocate the necessary capital demanded for the steady growth of their economy. The contributions of the stock market are latterly acknowledged among the developing countries. Bangladesh has maintained a remarkable sketch for growth and development despite of persistence political instability. Bangladesh is now renowned as an emerging economy and also repetitively pictured by reputed international organizations and media. The Dhaka stock exchange is very young as its extensive activity has started with the market liberalization in 1991, though it was formally started its trading in 1956. Market efficiency has continued in the central concept of the financial economics since 1960s. During the past more than 30 
years, there are many scholars have tried to test the market efficiency and random walk hypothesis from different markets all over the world with various methods, however, regarding to the developing market like the Bangladesh stock market, it is very few and infrequent. The term informational efficiency, i.e., market efficiency is the measure of how quickly and accurately the market reacts to new information. The father of the efficient market hypothesis, Eugene F. Fama (1965) assumes that stock prices are influenced by both fundamental and non-fundamental information. A liquid stock market is considered as efficient market when it absorbs very quickly and accurately all important unexpected information (Fama, 1970). Most of the researchers suggest that the developed markets are informationally efficient, while the emerging stock markets are inefficient.

Stock market of Bangladesh is not being a steady market. It is also well recognized that volatility characterizes the behavior of the stock market. But the problem is that market index increases for a while and accordingly the investors get pleasure from abnormal profit. In contrast, at times, the market falls hugely and thus investors acquire loss. The stock markets of Bangladesh already have faced two major collapses during the years 1996 and 2011. Thus, it is important to explore the performance of the stock market of Bangladesh by determining the level of efficiency based on the Efficient Market Hypothesis (EMH).

Investors and academics infrequently try to uncover whether stock returns in Bangladesh can be predicted with the help of past stock prices. The key the research question investigated in this study is whether the stock market of Bangladesh follows weak form of EMH or not. Thus, the objective of this paper is to investigate the existence of the random walk hypothesis (RWH) by testing the weak form efficiency in the returns of the Dhaka Stock Exchange (DSE). This paper makes an attempt to be a contribution to the limited literature on the emerging stock markets in particular the Bangladesh market. The study is organized in five sections as follows: Section 2 addresses the theoretical framework; Section 3 describes the literature review; Section 4 presents the data, methodology, and findings; and Section 5 reports conclusion.

\section{THEORETICAL FRAMEWORK}

The concept of market efficiency is considered central to finance and financial economics. Economists are mostly concerned with three types of efficiency in the capital market. These are allocational (Pareto) efficiency, operational efficiency, and informational efficiency. Allocational efficiency is concerned with the transfer of funds from savers to borrowers in the most productive manner. Operational efficiency states to the level of costs in carrying out transactions in the capital markets. Informational efficiency states to the magnitude to which all available information is incorporated into the prices of securities. The degree of allocational efficiency depends on both operational and informational efficiency, while financial market can be informationally efficient without being allocationally or operationally efficient. Usually, the empirical efforts on financial market efficiency emphasis on the informational market efficiency. Efficiency of equity markets has important implications for the investment policy of the investors. In an efficient stock market, prices of securities can generally be appropriately priced. Therefore, there will be no overvalued securities offering lower than expected return or undervalued securities offering higher than expected return. However, an inefficient market indicates that superior returns can consistently be sustained as information does not arrive in a random walk fashion, hence, abnormal returns can be obtained also by exposure to lower risk. Fama (1970) describes that EMH exists in various degrees such as weak, semi-strong and strong form subject to three different information sets. Weak form of EMH assumes that past stock prices are not significant to make an abnormal return. Semi-strong form of EMH presumes that no investor can earn abnormal returns using publicly available information. Finally a strong 
form of EMH assumes that all public and private information is reflected by present stock prices. Random walk model and technical analysis are the two methods that usually used to test weak form of EMH. Microeconomic and macroeconomic approaches, and fundamental analysis are methods of testing semi-strong form of EMH. Performance of mutual funds and insider trading behavior are the tools of testing strong form of efficiency.

The present study of testing weak form efficiency of DSE is based on the proposition that asset prices follow a random walk behavior, which implies that asset prices cannot be predicted. This framework is known as the Random Walk Hypothesis (RWH) or alternatively the weak form of EMH. If the hypothesis that the stock prices of DSE move randomly cannot be rejected, then it supports the weak form of market efficiency theory.

\section{LITERATURE REVIEW}

Groenewold and Kang (1993) examine the weak form efficiency of the Australian stock market using aggregate share price index's return employing autocorrelation test and unit root tests. Moreover, they investigate the semi-strong efficiency of the Australian stock market using aggregate share price indices and macroeconomic variables. By using 1980s data, both the tests reveal that the Australian stock market is consistent with the EMH.

Hassan, Islam, and Basher (2002) empirically examine the issue of market efficiency and time- varying volatility and equity returns for the equity market of Bangladesh using GARCH-M model over the 1990-1999 period. They have concluded that DSE departures from the efficient market hypothesis as DSE returns display significant serial correlation. The results also display a significant relationship between conditional volatility and the DSE stock returns. In his Paper, Moustafa (2004) employs serial correlations and runs tests to examine the behavior of stock prices using data on the daily prices of the 43 stocks included in the UAE market index covering the period from October 2, 2001 to September 1, 2003. The results reveal that the returns of 40 stocks out of the 43 are random at 5 percent level of significance, indicating that the UAE stock market follows weak-form efficiency of EMH.

Gupta and Basu (2007) find out the weak form of efficiency using daily index values for the Bombay Stock Exchange (BSE), and National Stock Exchange (NSE) of India over the period between 1991 and 2006. Using three unit root tests named ADF, PP, and KPSS, the study reveals that National Stock Exchange and Bombay Stock Exchange are not weak form efficient.

DePenya and Gil-Alana (2007) investigate the efficiency of the Spanish Stock Market indexes namely, IGBM (Indice General de laBolsa de Madrid), and IBEX35 from 4 January 1966 to 31 March 2002, and 14 January 1987 to 31 March 2002 respectively. The results show that the Spanish equity indexes (IGBM and IBEX35) are predictable until 1997, but not after that date. So, the stock returns of the Spanish Stock Market follow EMH after 1997.

Lagoarde-Segot and Lucey (2008) investigate informational efficiency using daily data ranging from 1 January 1998 to 16 November 2004 of the seven MENA stock market price indices from Morocco, Tunisia, Egypt, Lebanon, Jordan, Turkey and Israel. The research suggests that the MENA markets are predictable. Turkey and Israel exhibit the strongest evidence of weak-form efficiency. These markets are followed by Jordan, Tunisia, and Egypt, with Lebanon and Morocco lagging behind. The results also suggest that the extent of weak-form efficiency in the MENA stock markets is principally defended by differences in stock market size.

In their paper, Sharma and Mahendru (2009) examine the validity of the efficient market hypothesis in the Indian securities market taking a sample of eleven securities listed on the Bombay Stock Exchange (BSE) for the period from 30 June 2007 to 27 October 2007. By applying the runs tests and the autocorrelation tests, the results show that the BSE follows weak form of EMH as the current share prices already reflect the past share prices. 
Dicle and Levendis (2011) evaluate the Athens Stock Exchange efficiency both on the market and on the individual stock level. Evidence of inefficiencies is found, both on the market level and on the individual level. The study also reveals that about $94 \%$ of Greek stocks' returns are Granger caused by at least one foreign market. So, they conclude that the Greek market lacks the appeal for international diversification.

Hossain and Uddin (2011) empirically examine the efficiency and volatility effect of Dhaka Stock Exchange using three different daily price indices DGEN, DSI and DSE20 employing autocorrelation function, ADF and PP tests, ARIMA models, and GARCH (p, q) -M models. The results do not hold up the weak-form of EMH of DSE. The results of GARCH (p, q) -M models also indicate that DSE returns tend to display volatility clustering and investors are rewarded for taking increased risk for the securities of DS20 and DSI but not for DSEG. The study also reveals that a massive amount of capital inflow significantly influences the DSE volatility during the periods of caretaker government from 12 January 2007 to 6 January 2009. Khandoker, Siddik and Azam (2011) investigate the random walk hypothesis to test market efficiency in the Dhaka Stock Exchange, employing Runs test, Dickey-Fuller Unit root test using total 2403 daily observations of DGEN from 27 November 2001 to 19 May 2011, 2614 observations of DSI from 01 January 2000 to 19 May 2011, and 2649 daily observations of DSE-20 from 01 January 2001 to 19 May 2011. Daily closing prices of 30 companies operating in the bank sector are also considered as a proxy of movement of individual stock prices. The results reveal that DSE does not follow the random walk model, and therefore the Dhaka Stock Exchange is not efficient in weak form.

Charity and Sharmin (2012) test the weak form of efficiency, focusing on the random walk model for Dhaka Stock Exchange using DSI and DGEN Indices for the period of January 1, 1993 to June 30, 2011 and January 2002 to June 30, 2011 respectively. The results of serial correlation, autocorrelation test and ARIMA indicate that both indices of Dhaka Stock Exchange do not comply with the random walk model. The study concludes that the DSE is not Weak form of Efficient.

Nikita and Soekarn (2012) test the Weak Form Efficient Market Hypothesis in Indonesia's Stock Market using daily closing prices of IHSG and LQ45 composite index from 2008 to 2011. The autocorrelation, run test and a regression analysis are used to prove the signs of weak form market efficiency. The result displays the existence of non-randomness behavior and significant autocorrelation on IHSG and LQ45 index. Finally, they conclude that Indonesia Stock Market is not efficient in a weak form during the sample period.

Jumbo (2012) tests the weak-form efficient market hypothesis in the Nigerian Stock Exchange using all share index, and the five most traded and oldest bank stocks from January 2007 to December 2009 for the daily data, and from June 2005 to December, 2009 for the weekly data. The empirical outcomes derive from the autocorrelation tests, run tests and variance ratio tests for the observed returns conclusively settle that the NSE stock market is inefficient in the weak form. Employing Lo and MacKinlay's methodology, Nguyen, Islam, and Ali ( 2013) examine random walk model on the weekly movements of equity indices in Malaysia, the Philippines, and Taiwan over the period from the first week of 2000 to the second week of 2012. The results suggest that the equity markets in these Asian countries follow a random walk over the sample period.

Omar et al. (2013) examine the random walk behavior in the Karachi Stock Exchange using daily, weekly, and monthly stock returns of KSE 100 index for the period from 1 January 1998 to 29 February 2012 employing descriptive statistics, VAR test, RUN test, KS test and unit root tests (ADF test and PP). Results of all the tests specify that the KSE does not follow the random walk behavior and therefore, the KSE is not a weak form efficient. They conclude that there are chances of abnormal profit for the technical investors in the Pakistan stock market. 
Bose, Uddin, and Islam (2014) measure the efficiency level of Dhaka Stock Exchange and Chittagong Stock Exchange employing ARIMA test. The result of the study shows that Dhaka Stock Exchange and Chittagong Stock Exchanges are not in the form of weak efficiency and strong efficiency. They conclude that both stock markets belong to the semi strong form of efficiency, and Chittagong Stock Exchange is more efficient than Dhaka Stock Exchange.

\section{Methodology and Findings}

This part of the study covers the research methodology to seek out the results of research question. Several statistical and econometric tools are operated to get the answer of the research question of this study. We have used both parametric and non-parametric tests to avoid the bias resulting from non-normal distribution of the data. Non- Parametric tests include Runs test and Phillips-perron test. Parametric tests include Autocorrelation coefficient test, Augmented Dickey-fuller test, and Variance Ratio test. A comprehensive description of these examinations and the results subsequently are described below.

\section{Data and Data Sources}

Bangladesh has two stock exchanges: Dhaka Stock Exchange (DSE) and Chittagong Stock Exchange (CSE). Dhaka Stock Exchange is the oldest and largest stock exchange in Bangladesh. DSE used three share price indices- All Share Price Index (DSI), General Price Index (DGEN) and DSE-20 before starting Standards \& Poor's supported DSE Broad Index (DSEX) \& DSE 30 Index (DS30) in 28 January 2013. In the current analysis, we use daily data for the three stock Indices on DSE. The three indices used are:

- DSI: DSI formed with all enlisted securities excluding mutual funds, bonds, and debentures. The daily closing prices of DSI are used in the current study from 02 January 1993 to 27 January 2013 with a total of 4823 daily return observations.

- DGEN: DGEN Index formed by excluding Z-category securities, mutual fund, bonds, and debentures. The daily closing prices of DGEN are used from 01 January 2002 to 31 July 2013 with a total of 2903 daily return observations.

- DSE-20: DSE-20 structured with the 20 best enlisted companies depending on performance and specific criteria. The daily closing prices of DSE-20 are used for the study from 01 January 2001 to 27 January 2013 with a total of 3047 daily return observations.

All the index data are collected from the central library of the Dhaka Stock Exchange. The analysis is done by using the EViews 7.1 econometric software packages. The daily index data of three indices of different periods obtained from DSE are used to calculate returns as follows:

$\mathrm{R}=\operatorname{Ln}\left(\frac{P_{t}}{P_{t-1}}\right) \times 100$

where, $\mathrm{R}=$ Daily return, $\mathrm{Ln}=$ Natural $\log , \mathrm{P}_{\mathrm{t}}=$ Price Index at time $\mathrm{t}$, and $\mathrm{P}_{\mathrm{t}-1}=$ Price Index at time $\mathrm{t}-1$.

\section{Data Statistics}

This subsection provides descriptive statistics for the data under study and the purpose is check to for the normality of the data. One of the basic assumptions of the random walk model is that the distribution of the return series should be normal. The following Table I gives a summary of the statistical features of the variables. We notice that the average monthly returns are positive for all the indices over the sample period. However, the average values do not conclusively suggest that the DSE has profitable in the short term, as we see that the large spread between the 
minimum and maximum values. The positive skewness values for all the indices suggest that these variables have right tails, while DSI returns are strongly skewed right, and DGEN and DSE-20 returns are moderately skewed right. The value of skewness and kurtosis of stock return series of DSE are not equal to 0 and 3 respectively. So, data are not normally distributed. The calculated Jarque-Bera statistics and p-values in the table I are used to test the null hypothesis for normal distribution (H0: Daily distribution of stock market returns is normally distributed). The p-values for all the indices are less than $(0.01)$ at the $1 \%$ level of significance imply that the null hypothesis cannot be accepted. Hence, the non-normal frequency distributions of the stock returns deviate from the prior condition of the random walk model.

Table I: Descriptive Statistics for Daily Market Returns of DSE

\begin{tabular}{|c|c|c|c|}
\hline & DSI & DGEN & DSE-20 \\
\hline Mean & 0.046789 & 0.056814 & 0.031962 \\
\hline Median & 0.000757 & 0.049725 & 0.000000 \\
\hline Maximum & 59.90334 & 20.38212 & 14.79510 \\
\hline Minimum & -24.95818 & -9.329968 & -8.992433 \\
\hline Std. Dev. & 1.844108 & 1.511689 & 1.367038 \\
\hline Skewness & 7.709156 & 0.822605 & 0.290007 \\
\hline Kurtosis & 257.5930 & 21.48107 & 13.67005 \\
\hline Jarque-Bera & 13073409 & 41640.73 & 14496.90 \\
\hline Probability & 0.000000 & 0.000000 & 0.000000 \\
\hline Observations & 4823 & 2903 & 3047 \\
\hline
\end{tabular}

\section{Autocorrelation Test}

The autocorrelation test is a parametric test that used to investigate whether autocorrelation or serial correlation presents or not in the consecutive returns of time series DSI, DGEN and DSE-20 data. Serial correlation test, also known as autocorrelation test, measures the correlation coefficient between a series of returns and lagged returns in the same series. The autocorrelation coefficient $\rho_{\mathrm{k}}$ measures the degree of correlation between the current stock return $R_{t}$ and the return separated by $K$ lags $R_{t-k}$ (Tsay, 2005). It can be computed as the ratio of the covariance between ${ }_{t} R$ and ${ }_{t} R_{-k}$ to the product of their standard deviations:

$\rho_{k}=\frac{\operatorname{COV}\left(R_{t}, R_{t-k}\right)}{\sigma\left(R_{t}\right)\left(R_{t-k}\right)}=\frac{E\left[\left(R_{t}-\mu\right)\left(R_{t-k}-\mu\right)\right]}{E\left[\left(R_{t}-\mu\right)^{2}\right]}$

A significant positive serial correlation suggests that a trend be present in the series, while, a negative serial correlation indicates the existence of reversal in price movements. A return series that is truly random may have a zero serial correlation coefficient. If the stock series practice a random walk, there will be no significant serial dependence.

Autocorrelation coefficient at lag $\mathrm{k}$ can be estimated as:

$$
\hat{\rho}_{\mathrm{k}}=\frac{\sum_{\mathrm{t}=1}^{\mathrm{n}-\mathrm{k}}\left[\left(\mathrm{R}_{\mathrm{t}}-\overline{\mathrm{R}}\right)\left(\mathrm{R}_{\mathrm{t}-\mathrm{k}}-\overline{\mathrm{R}}\right)\right]}{\sum_{\mathrm{t}=1}^{\mathrm{n}}\left(\mathrm{R}_{\mathrm{t}}-\overline{\mathrm{R}}\right)^{2}}
$$

where $\hat{\mathrm{R}}$ is the sample mean of stock returns.

Since the existence of autocorrelation is a very powerful result with regards to weak form of efficiency of EMH, Ljung-Box $Q$ statistics is used to investigate whether autocorrelation 
exists or not. The Ljung-Box Q test (Ljung and Box, 1978) is a modification of the original Box-Pierce $Q$ test and can be computed as:

$\mathrm{Q}_{\mathrm{k}}=\mathrm{N}(\mathrm{N}+2) \sum_{\mathrm{j}=1}^{\mathrm{k}} \frac{\hat{\rho_{j}^{2}}}{\mathrm{~N}-\mathrm{j}}$

where $\hat{\rho_{\mathrm{j}}}$ is the sample autocorrelation coefficient at lag $\mathrm{j}$.

The following null and alternative hypotheses are tested:

$\mathrm{H}_{0}$ : DSE returns are not independent (i.e., autocorrelation)

$\mathrm{H}_{1}$ : DSE returns are independent (i.e., no autocorrelation).

Table II: Tests for Serial Correlation in Daily DSE Stock Returns in Level

\begin{tabular}{|c|c|c|c|c|c|c|c|c|c|}
\hline \multirow{2}{*}{ Lags } & \multicolumn{4}{|c|}{ DSI } & \multicolumn{3}{c|}{ DGEN } & \multicolumn{3}{c|}{ DSE-20 } \\
\cline { 2 - 10 } & AC & Q-stat & P-value & AC & Q-stat & value-P & AC & Q-stat & P-value \\
\hline 1 & 0.100 & 48.204 & 0.000 & 0.039 & 4.3188 & 0.038 & 0.054 & 8.7848 & 0.003 \\
\hline 2 & -0.017 & 49.627 & 0.000 & -0.041 & 9.2371 & 0.010 & -0.031 & 11.730 & 0.003 \\
\hline 3 & 0.005 & 49.742 & 0.000 & 0.001 & 9.2382 & 0.026 & 0.021 & 13.027 & 0.005 \\
\hline 4 & 0.023 & 52.377 & 0.000 & 0.025 & 10.998 & 0.027 & 0.025 & 14.969 & 0.005 \\
\hline 5 & 0.031 & 57.009 & 0.000 & 0.022 & 12.359 & 0.030 & 0.008 & 15.181 & 0.010 \\
\hline 6 & -0.013 & 57.817 & 0.000 & -0.013 & 12.817 & 0.046 & 0.004 & 15.232 & 0.019 \\
\hline 7 & 0.011 & 58.446 & 0.000 & -0.001 & 12.820 & 0.077 & -0.021 & 16.518 & 0.021 \\
\hline 8 & 0.025 & 61.529 & 0.000 & 0.018 & 13.802 & 0.087 & 0.006 & 16.636 & 0.034 \\
\hline 9 & 0.017 & 62.977 & 0.000 & 0.060 & 24.433 & 0.004 & 0.044 & 22.502 & 0.007 \\
\hline 10 & 0.036 & 69.149 & 0.000 & 0.011 & 24.808 & 0.006 & 0.004 & 22.553 & 0.013 \\
\hline 15 & 0.011 & 74.532 & 0.000 & 0.034 & 34.909 & 0.003 & 0.040 & 38.730 & 0.001 \\
\hline 20 & -0.010 & 77.719 & 0.000 & -0.033 & 43.117 & 0.002 & -0.025 & 48.927 & 0.000 \\
\hline 25 & -0.009 & 89.812 & 0.000 & -0.044 & 66.647 & 0.000 & -0.049 & 74.113 & 0.000 \\
\hline 30 & -0.006 & 96.341 & 0.000 & 0.014 & 67.582 & 0.000 & 0.033 & 78.711 & 0.000 \\
\hline
\end{tabular}

Tests for the absence of serial correlation over time between returns are implemented from lag 1 to lag 30 for the three indices. Table II shows that there is highly significant autocorrelation for all lags at the $1 \%$ level for the returns of DSI on the base of the Box-Pierce test. The autocorrelation test for the return series of DGEN index also exhibits significant autocorrelation for lags 9 to 30 at the 1\% level, while for lags 1 to 6 at the $5 \%$ level, and for lags 7 to 8 at the $10 \%$ level. On the other hand, there is highly significant autocorrelation in DSE-20 return series for all lags at the $1 \%$ level except for lags 5, 6, 7, 8, and 10. However, DSE-20 return series also displays significant autocorrelation at the $5 \%$ level for lags 5, 6, 7, 8, and 10 . To confirm the results, the autocorrelation coefficient of the return series for first differences are also calculated. Table III shows that there is highly significant autocorrelation for all lags at the $1 \%$ level for all the returns of DSI indices for the first differences. 
Table III: Tests for Serial Correlation in Daily DSE Stock Returns in First Differences

\begin{tabular}{|c|c|c|c|c|c|c|c|c|c|}
\hline Variables & Lags & 1 & 2 & 3 & 4 & 5 & 10 & 20 & 30 \\
\hline \multirow{2}{*}{ (DSI) } & Q-stat & 912.7 & 941.6 & 941.6 & 941.8 & 945.7 & 957.4 & 984.1 & 996.6 \\
\cline { 2 - 10 } & P & 0.000 & 0.000 & 0.000 & 0.000 & 0.000 & 0.000 & 0.000 & 0.000 \\
\hline \multirow{2}{*}{ D(DGEN) } & stat-Q & 610.6 & 622.2 & 622.5 & 623.1 & 623.8 & 633.1 & 669.1 & 692.9 \\
\cline { 2 - 9 } & P & 0.000 & 0.000 & 0.000 & 0.000 & 0.000 & 0.000 & 0.000 & 0.000 \\
\hline \multirow{2}{*}{ (DSE-20) } & stat-Q & 631.9 & 647.7 & 649.6 & 650 & 650.1 & 657.9 & 714.7 & 754.0 \\
\cline { 2 - 8 } & P & 0.000 & 0.000 & 0.000 & 0.000 & 0.000 & 0.000 & 0.000 & 0.000 \\
\hline
\end{tabular}

The nonzero auto-correlation of all the series associated with Ljung -Box Q statistics suggest that the DSI, DGEN, and DSI-20 return series do not follow random walk model. So, the serial autocorrelation test reveals that the DSE is not weak form efficient as stock prices do not follow a random walk.

\section{Run Test}

The Run Test, also named Geary test, is one of the typical non-parametric tests for serial dependence of time series. In run test, the number of sequences of consecutive positive and negative returns is tabulated and compared against its sampling distribution under the random walk hypothesis (Gujrati, 2003 ). So, a run is outlined as the repeated occurrence of the same value or category of a variable. It is indexed through parameters, which are the type of the run and the length. Stock price runs can be positive, negative, or have no change. The length is how steadily a run type occurs in succession. Under the null hypothesis that successive outcomes are unbiased, the total expected number of runs is distributed as normal with the following mean:

$N(N+1)-\sum_{i=1}^{3} n_{i}^{2}$

$$
N
$$

where $\mathrm{N}$ is the total number of return observations and $n_{i}$ is the number of runs of type $i$.

The standard normal Z-statistic $\left(Z=(R-\mu) / \sigma_{\mu}\right)$ is carried out to test of serial dependence by comparing the actual number of runs in the price series to the expected number $\mu$. The null hypothesis is $\mathrm{H}_{0} \mathrm{E}$ (runs) $=\mu$. When the actual number of runs exceed (fall below) the expected runs, a positive (negative) $\mathrm{Z}$ value is obtained. Positive (negative) $\mathrm{Z}$ value indicates negative (positive) serial correlation in the return series.

The results of the runs test for all DSE return series are reported in Table IV. As can be observed from the Table, the Z-statistics of the runs test of serial independence are significant at the one percent level. The significant negative $Z$-values for the returns indicate that the actual number of runs is less than the expected number of runs. So, there is a significant positive serial correlation in all the return series. The findings are consistent with the previous findings of auto-correlation tests, showing that the Dhaka Stock Exchange does not follow random walk.

Table IV: Runs Test for the DSE Stock Returns

\begin{tabular}{|l|c|c|c|c|c|c|}
\hline Return Series & Observations & $\mathrm{N}(<=$ mean $)$ & $\mathrm{N}(>$ mean $)$ & Runs & Z & P-value \\
\hline DSI & 4823 & 2763 & 2060 & 1702 & -19.4 & 0.000 \\
\hline DGEN & 2903 & 1465 & 1438 & 1229 & -8.299 & 0.000 \\
\hline DSE-20 & 3047 & 1568 & 1479 & 1251 & -9.869 & 0.000 \\
\hline
\end{tabular}




\section{Unit Root Test}

The time series move either upwards and downwards with or without trend are known as random walks. These AR(1)-OLS and random walk can be estimated via unit root tests. Unit root is a necessary condition for a random walk. Three regression models without intercept and trend, intercept with no trend, and intercept with trend are used in this study to test for unit root. Two extensively used unit root test, namely Augmented Dickey Fuller (ADF) and Phillips-Peron (PP) test are employed to examine the stationarity of the time series. ADF is the augmented form of Dickey Fuller test. The ADF test is performed using the following equation:

$\Delta Y_{t}=\alpha+\beta t+\gamma Y_{t-1}+\delta_{1} \Delta Y_{t-1}+\ldots \ldots+\delta_{\rho} \Delta Y_{t-\rho}+\varepsilon_{t}$

where, $\alpha$ is a constant, $\beta$ is the coefficient of time trend, $\gamma, \delta$ are the parameters, $\rho$ is the lag order of the autoregressive process, $\Delta \mathrm{Y}$ is the first difference of $\mathrm{Y}$ series and $\varepsilon$ is the error term.

Phillips and Perron (1988) have developed a non-parametric unit root conception. The PP test of the following model is estimated:

$\Delta Y_{t}=\alpha+\beta t+\gamma Y_{t-1}+\varepsilon_{t}$

where, $\alpha$ is a constant, $\beta$ is the coefficient of time trend, $\gamma$ is the parameter and $\varepsilon$ is the error term.

Whilst the ADF test addresses lags of $\Delta \mathrm{Y}$ as regressors in the test equation, the PP test forces a non-parametric correction to the t-test statistic. The PP tests correct for any serial correlation and heteroscedasticity in the errors $\varepsilon_{t}$ of the test regression by directly modifying the test statistic. The unit root test (ADF and $\mathrm{PP}$ ) results of random walk model are presented in the following Table V and VI respectively.

Table V: Results of Augmented Dickey Fuller (ADF) Test

\begin{tabular}{|c|c|c|c|c|}
\hline $\begin{array}{c}\text { Return } \\
\text { Series }\end{array}$ & $\begin{array}{c}\text { Without intercept } \\
\text { and trend }\end{array}$ & $\begin{array}{c}\text { Intercept with } \\
\text { no trend }\end{array}$ & $\begin{array}{c}\text { Intercept } \\
\text { with trend }\end{array}$ & Remarks \\
\hline DSI & -62.77181 & -62.80204 & -62.79559 & No Unit Root \\
& $(-2.565442)$ & $(-3.431524)$ & $(-3.959941)$ & \\
\hline DGEN & -51.75276 & -51.81367 & -51.81173 & No Unit Root \\
& $(-2.565759)$ & $(-3.432413)$ & $(-3.961204)$ & \\
\hline DSE-20 & -52.26729 & -52.28594 & -52.28430 & No Unit Root \\
& $(-2.565721)$ & $(-3.432307)$ & $(-3.961054)$ & \\
\hline
\end{tabular}

Note: MacKinnon $1 \%$ critical values for the ADF statistic are in brackets.

Table VI: Results of Phillips-Peron (PP) Test

\begin{tabular}{|c|c|c|c|c|}
\hline $\begin{array}{c}\text { Return } \\
\text { Series }\end{array}$ & $\begin{array}{c}\text { Without intercept } \\
\text { and trend }\end{array}$ & $\begin{array}{c}\text { Intercept with } \\
\text { no trend }\end{array}$ & $\begin{array}{c}\text { Intercept } \\
\text { with trend }\end{array}$ & Remarks \\
\hline DSI & -63.20936 & -63.17421 & -63.16799 & No Unit Root \\
& $(-2.565442)$ & $(-3.431524)$ & $(-3.959941)$ & \\
\hline DGEN & -51.73912 & -51.79103 & -51.78859 & No Unit Root \\
& $(-2.565759)$ & $(-3.432413)$ & $(-3.961204)$ & \\
\hline DSE-20 & -52.25114 & -52.25766 & -52.25580 & No Unit Root \\
& $(-2.565721)$ & $(-3.432307)$ & $(-3.961054)$ & \\
\hline
\end{tabular}

Note: MacKinnon $1 \%$ critical values for the PP statistic are in brackets.

From the Table V, the ADF test results clearly reveal that the null hypothesis of unit root is strongly rejected at one percent significant level. It specifies that all the return series are stationary, then they do not follow a random walk. The Phillips- Perron tests also give us a 
more negative t-statistic compared with the critical values calculated at one percent level of significance (Table VI). The results of PP test are consistent with the findings of ADF test as it also rejects the null hypothesis of the series being random suggesting that the market is not weak form efficient.

\section{The Variance Ratio Test}

Lo and Mackinlay (1988) developed a simple specification test for evaluating the random walk properties of asset prices. Both academics and practitioners argue that variance ratio test is more reliable than traditional tests of unit root (ADF, PP) and serial correlation tests (Box-Pierce). If VR (q) statistic is significantly different from unity, the hypothesis should be rejected with evidences of autocorrelations in return series. A variance ratio that is greater than one suggests that returns series is positively serially correlated. A variance ratio that is less than one suggests that the return series is negatively serially correlated.

Table VII: Variance Ratio Estimates and Test Statistics of RWH

\begin{tabular}{|l|c|c|c|c|c|}
\hline Return Series & Period & VR $(\mathrm{q})$ & Z-Statistics & P-Value & Remarks \\
\hline \multirow{4}{*}{ DSI } & 2 & 0.565290 & -3.294388 & 0.0010 & \multirow{5}{*}{} \\
\cline { 2 - 5 } & 4 & 0.271604 & -3.661275 & 0.0003 \\
\cline { 2 - 5 } & 8 & 0.187950 & -3.655145 & 0.0003 \\
\cline { 2 - 5 } & 16 & 0.071118 & -3.618938 & 0.0003 \\
\hline \multirow{5}{*}{ DGEN } & 2 & 0.541801 & -8.293372 & 0.0000 & \multirow{3}{*}{ Rejected } \\
\cline { 2 - 5 } & 4 & 0.254029 & -8.283722 & 0.0000 & \\
\cline { 2 - 5 } & 8 & 0.127828 & -7.315855 & 0.0000 \\
\cline { 2 - 5 } & 16 & 0.064107 & -5.851157 & 0.0000 \\
\cline { 2 - 5 } & 2 & 0.545046 & -8.871108 & 0.0000 \\
\cline { 2 - 5 } & 4 & 0.257958 & -8.594984 & 0.0000 \\
\cline { 2 - 5 } & 8 & 0.131805 & -7.378530 & 0.0000 & \\
\cline { 2 - 5 } & 16 & 0.066062 & -5.673763 & 0.0000 & \\
\hline
\end{tabular}

The variance ratio VR $(q)$ is defined as:

$\operatorname{VR}(\mathrm{q})=\frac{\sigma^{2}(q)}{\sigma^{2}(1)}$

where $\sigma^{2}$ (q) is $1 / \mathrm{q}$ the variance of the $\mathrm{q}$-differences and $\sigma^{2}(1)$ is the variance of the first differences. For that, $\mathrm{H}_{0}$ : VR $(q)=1$ means markets under the study are weak-form efficient, $\mathrm{H}_{\mathrm{a}}$ : VR (q) $\neq 1$ means markets under the study are not weak-form efficient.

Table VII demonstrates variance ratio estimates and test statistics of RWH for the entire study period based on the methodology of conventional variance ratio test by Lo and MacKinlay (1988). The variance ratio is computed for multiples of 2, 4, 8, and16 days, with the one-day return used as the base. The results for all indices reveal that the variance ratios are deviated from 1 significantly. Therefore, the variance ratio test rejects the RWH for the DSE, accordingly the Dhaka Stock Exchange is not efficient in weak-form.

\section{CONCLUSION}

The stock market efficiency is always an important topic to academicians and practitioners. Stock market of Bangladesh is relatively new compared to other emerging countries but gets an immense focus by policymakers, investors, academicians, and even general citizens. Hence, the present study adds some contributions to the existing literature in context of the 
Bangladeshi stock market. In the above analysis, we investigate the Random Walk Hypothesis in order to comment about the weak form efficiency of Dhaka Stock Exchange. The study uses a various tests both parametric as well as non-parametric to arrive at the objective of the study employing return series of DSI, DGEN, and DSE-20 for the period of 02 January 1993 to 27 January 2013, 01 January 2002 to 31 July 2013, and 01 January 2001 to 27 January 2013 respectively. The conclusion drawn from the study is that the indices of Dhaka Stock Exchange are not followed RWM and therefore the market is weak form inefficient.

All the statistical and econometric tools such as normality tests, autocorrelation test, unit root tests, runs test, and variance ratio test used for the study clearly reveal that the Dhaka Stock Exchange is inefficient in weak form. This finding is consistent with the results of Hassan, Islam, and Basher (2002), Khandoker, Siddik, and Azam (2011), Chaity and Sharmin (2012) for the Bangladesh stock market, and other empirical studies such as Gupta and Basu (2007), for the Indian stock market, Gima (2012) for the Nigerian stock market, and Omar et al. (2013) for the Pakistan stock market. These results defend the common belief that the equity markets in the emerging economies are not efficient. So, there will be always a scope of technical analysis in the Bangladeshi stock markets as long as they continue to be efficient. It mentions that some investors can earn abnormal profits, whereas some acquire enormous losses from the capital market of Bangladesh. This phenomenon prevents the smooth functioning of stock markets of Bangladesh and adversely affect the performance of the economy. Thus, Bangladesh Securities and Exchange Commission (BSEC) should sincerely strengthen its effort in improving capital market infrastructure to build an efficient stock market. Future studies can find out the causes of the inefficiency and suggest ways as to how DSE can become efficient within a short period.

\section{REFERENCES}

Bose, TK, Uddin, R \& Islam, W 2014 , 'Measuring and Comparing the Efficiency of Dhaka Stock Exchange and Chittagong Stock Exchange' International Journal of Scientific and Research Publications, vol. 4, no. 3, pp. 1-14.

Chaity, NS \& Sharmin, S 2012, 'Efficiency Measures of Capital Market: A Case of Dhaka Stock Exchange, International Journal of Business and Management, vol. 7, no. 1, pp. 102-108, doi:10.5539/ijbm.v7n1p102

DePenya, FJ \& Gil-Alana, LA 2007, 'Serial correlation in the Spanish Stock Market', Global Finance Journal, vol. 18, no. 1, pp. 84-103, doi:10.1016/j.gfj.2007.01.001

Dicle, MF \& Levendis, J 2011, 'Greek market efficiency and its international integration', Journal of International Financial Markets, Institutions and Money, Vol. 21, no. 2, pp. 229-246, doi:10.1016/j.intfin.2010.10.005

Fama, EF 1965, 'The Behavior of Stock Market Prices', Journal of Business, vol. 38, no. 34-105.

Fama, EF 1970, 'Efficient Capital Markets: A Review of Theory and Empirical Work', Journal of Finance, vol. 25, no. 2, pp. 383-415.

Gimba, VK 2012, 'Testing the Weak-form Efficiency Market Hypothesis: Evidence from Nigerian Stock

Groenewold, N \& Kang, K 1993, 'The semi-strong efficiency of the Australian share market', Economic Record, vol. 69, no. 207. pp. 405-410.

Gujarati, DN 2004, Basic Econometrics, 4th edn, The McGraw-Hill Companies, New Delhi.

Gupta, R \& Basu, PK 2007, 'Weak Form Efficiency In Indian Stock Markets', International Business \& Economics Research Journal, vol. 6, no. 3, pp. 57-64.

Hassan, MK, Islam, MA \& Basher, SA 2002, Market efficiency, time-varying volatility and equity returns in Bangladesh stock market, Working Papers 2002-2006, Department of Economics, York University, viewed 02 August 2013, http://dept.econ.yorku.ca/research/workingPapers/working papers/DSE.pdf

Hossain, MS \& Uddin, MGS 2011, Efficiency Analysis and Volatility Effect of Bangladesh Stock Market, 
paper presented at the 2011 Cambridge Business \& Economics Conference, 27-28 June, Cambridge University, UK, viewed 16 August www.gcbe.us/2011_CBEC/data/Sharif\%20Hossain,\%20Gazi\%20Salah\%20Uddin.doc

Khandoker, MSH, Siddik, MNA \& Azam, M 2011, 'Tests of Weak-form Market Efficiency of Dhaka Stock Exchange: Evidence from Bank Sector of Bangladesh', Interdisciplinary Journal of Research in Business, vol. 1, no. 9, pp.47- 60 .

Lagoarde-Segot, T \& Lucey, BM2008, 'Efficiency in emerging markets-Evidence from the MENA region', Journal of International Financial Markets, Institutions and Money, vol.18, no.1, pp. 94-105, doi:10.1016/j.intfin.2006.06.003

Lo, A, \& MacKinlay, C 1988, 'Stock market prices do not follow random walks: Evidence from a simple specification test', Review of Financial Studies, vol. 1, pp. 41-66.

Market', CBN Journal of Applied Statistics, vol. 3, no.1, pp. 117- 136.

Moustafa, MA, 2004, 'Testing the Weak-Form Efficiency of the United Arab Emirates Stock Market', International Journal of Business, vol. 9, no. 3, pp. 309-325.

Nguyen, CV, Islam, AM \& Ali, MM2013, 'Equity Price Indices and Random Walk: The Case of Malaysia, the Philippines and Taiwan', International Review of Business Research Papers, vol. 9, no. 5, pp. 28-38.

Nikita, MP \& Soekarno, S 2012, Testing on Weak Form Market Efficiency: The Evidence from Indonesia Stock Market Year 2008-2011, paper presented at the 2nd International Conference on Business, Economics, Management and Behavioral Sciences, 13-14 October, Bali, Indonesia, viewed 3 September 2014, http://psrcentre.org/images/extraimages/1012504.pdf

Omar, M, Hussain, H, Bhatti, GA \& Altaf, M 2013, 'Testing of random walks in Karachi stock exchange', Finance Management, vol. 54, pp. 12293-12299.

Sharma, GD \& Mahendru, M 2009, 'Efficiency Hypothesis of the Stock Markets: A Case of Indian Securities', International Journal of Business and Management, vol. 4, no. 3, pp. 136-144.

Tsay, RS 2010, Analysis of Financial Time Series, Second Edition, Wiley-Interscience, New York. 